\title{
The significance of the fluorescent treponemal antibody (FTA-ABS) test in collagen disorders and leprosy
}

\author{
D. J. M. WRIGHT \\ From the Department of Medicine, Guy's Hospital, London
}

SYNOPSIS A test is described to distinguish the immunofluorescence seen on T. pallidum in syphilis $\frac{\circ}{\vec{N}}$ from that due to antibodies against DNA.

The method consists of comparing the results of the fluorescent treponemal antibody (FTA-ABS) test with the staining obtained with $T$. gondii and $T$. cruzi using an indirect fluorescent technique. The $\subseteq$ ability of a particular serum to stain other organisms, in addition to $T$. pallidum, at a significant titre indicates that the treponemal fluorescence is not specific, and the loss of this staining property when organisms are pretreated with deoxyribonuclease suggests that the common microbial antigen is DNA. The isolated treponemal fluorescence found in syphilis is unaffected by pretreatment of T. pallidum.

When 123 sera from patients with collagen disorders were examined, non-specific bacterial fluop escence was observed in six sera, while in 95 sera from patients with lepromatous leprosy, a positi FTA-ABS reaction was obtained in 14. There was no accompanying immunofluorescence on othe protozoa. Therefore the antibody reacting in the FTA-ABS test in leprosy is likely to be treponemat in origin. A mitochondrial antibody was found in seven out of the 15 sera from patients with lepromatous leprosy.

Positive fluorescent treponemal antibody tests may rarely occur in diseases other than syphilis, in particular, in collagen disorders (Kraus, Haserick, and Lantz, 1970). Scotti, Mackey, and Trautman (1970) have suggested that the immunofluorescent treponemal reaction seen in leprosy is akin to that found in collagen disorders and may be caused by a common aetiological factor.

\section{Origin of Test Sera}

Two hundred and seventy-eight sera were studied; 95 sera were taken from patients with histologically proven untrated lepromatous leprosy from a Malayan leprosarium. No comparable control sera from Malaya were available for testing. Ten sera were from patients with syphilis and 123 sera from patients with collagen disorders. The nature of the collagen disorder is shown in table I. Fifty sera from clinically

${ }^{1}$ In receipt of an MRC grant.

Received for publication 31 August 1973.

\begin{tabular}{lrll}
\hline Disease & $\begin{array}{l}\text { No. } \\
\text { Tested }\end{array}$ & $\begin{array}{l}\text { Positive } \\
\text { FTA }(\text { ABS })\end{array}$ & $\begin{array}{l}\text { Other Confirmatory } \\
\text { Tests for Syphilis }\end{array}$ \\
\hline Systemic lupus & & & \\
erythematosus & 71 & $5(7.0 \%)$ & 1 \\
Sjggren's syndrome & 17 & 1 & 1 \\
Polyarteritis nodosa & 16 & 0 & 1 \\
Rheumatoid arthritis & 10 & 4 & 2 \\
Miscellaneous & 5 & 1 & 0 \\
collagenoses & 2 & 0 & 0 \\
Scleroderma & 2 & 0 & 0 \\
Lupoid hepatitis & 123 & $11(9 \%)$ & 5 \\
Total & &
\end{tabular}

Table I The fuorescent treponemal antibody (ABS) test in collagen disorders

normal patients attending the venereal disease clinic 0 at Guy's Hospital, London, were also used as 6 controls.

\section{Immunofluorescent Tests}

Suspensions of organisms were dried on clear areas 
of slides, treated with a teflon (Hiflon PTFE. Gallenkamp) water repellent (Goldman, 1968). The National Communicable Disease Centre Manual of Serology (1969) was followed with slight modifications when carrying out the fluorescent antibody test. It was not found necessary to inactivate the serum at $56^{\circ} \mathrm{C}$ and the test was conducted at room temperature. When staining with serum and conjugate the buffer did not contain $2 \%$ Tween 80 . Fresh treponemes were used in this test, since stored spirochaetes may give a confusing, discontinuous, patchy immunofluorescent pattern.

The technique was applied to Trypanosoma cruzi, using a reconstituted lyophilized preparation and Toxoplasma gondii ( $\mathrm{R}$ strain). Immunofluorescent tests were also carried out on organisms pretreated with deoxyribonuclease DNAase (Sigma Laboratories) (Kraus, Haserick, Logan, and Bullard, 1971).

Serum was taken in $5 \mu$ l amounts and diluted 1 in 5 in sorbent (for the FTA-ABS test) and 1 in 50 in phosphate-buffered saline for immunofluorescent tests on the protozoa. Specific goat antihuman IgG conjugates (Wellcome Reagents) were used at a dilution of 1 in 60 . Results were recorded as negative, equivocal, weak positive, or positive. There was no differentiation between +++ and ++++ as used in the routine FTA-ABS test. The presence of thyroid microsomal, gastric parietal antibodies, and antinuclear factor were looked for, following the method outlined in the World Health Organization Manual of Auto-Immuno Serology (1969). The microscope used was a Zetopan (Reichert) with an Hb200 high pressure mercury vapour lamp. All tests were carried out in duplicate and read independently by two observers, concordance being required for assessment of the result as positive.

The absorbing potency of sorbent (Wellcome Reagents) was estimated using human non-specific positive control sera. These were tested at dilutions of 1 in 5,1 in 25 , and 1 in 125 in saline and sorbent against $T$. pallidum and $T$. reiteri. The test sera were also absorbed with an equal volume of a Reiter treponeme suspension.

\section{Tests for Syphilis}

The Wassermann antibody was assayed by the VDRL test (National Communicable Disease Centre, 1969) and the cardiolipin fluorescent antibody test (Wright, Doniach, Lessof, Turk, Grimble, and Catterall, 1970) using frozen rat and human kidney antigens. The Reiter protein complement-fixation test (RPCFT) (Wilkinson, 1969) and the treponemal haemagglutination antibody (TPHA) test (Johnston, 1972) were carried out on all sera giving a positive reaction with one of the other tests.

\section{Results}

The finding of positive fluorescent treponemal antibody absorption tests was confirmed in 11 of our 123 sera from patients with collagen disorders. Of these 11 sera, five were found to have positive Reiter protein complement-fixation reactions and treponemal haemagglutination tests in addition to the presence of fluorescent treponemal antibodies. Absorption of sera with Reiter treponemes removed the treponemal fluorescence found both in association and with absent confirmatory tests for syphilis.

The frequency of the fluorescent treponemal antibody test in different collagen diseases is shown in table I. The finding of a positive fluorescent treponemal antibody absorption test in a patient with Sjøgren's syndrome has not been previously reported. Sjøgren's syndrome is not a recognized complication of syphilis.

The sera in this case came from an alcoholic female, aged 54, who had had a crusting skin eruption and meningitis, which had responded to penicillin 22 years earlier. Since the age of 49 , she had progressive enlargement of the salivary and lacrimal glands. She was diagnosed as having kerato-conjunctivitis sicca at Moorfields Eye Hospital, London. Confirmatory tests for syphilis were positive; liver function tests were negative. No evidence of amyloidosis was found.

The finding of other autoantibodies in sera from 123 patients with collagen disorders was unrelated to the presence of positive fluorescent treponemal absorption tests. Out of 47 sera containing antinuclear factors in the IgG class, only seven reacted in the fluorescent treponemal antibody absorption test. There was no significant relation between the two tests $(P<0.001)$. The statistical procedure used was at test on percentages. Ten sera contained thyroid microsomal antibodies and gastric parietal antibodies, none of which gave treponemal fluorescence, while, out of the 38 sera giving VDRLreactions, five gave positive fluorescent treponemal antibody reactions. In four of these sera, other positive confirmatory tests for syphilis were elicited.

Three out of the six sera with positive fluorescent treponemal antibody absorption tests, in the absence of positive confirmatory tests for syphilis, gave a beaded treponemal fluorescence. This was not found on every one of the stained spirochaetes in the smear (see figure). When deoxyribonuclease-treated treponemes were used as the antigen in the fluorescent treponemal antibody absorption test, all fluorescences, including those with beaded patterns, were eliminated in four cases out of nine as were those when DNAase-treated protozoal substrates were used. The remaining five positives all gave a homo- 


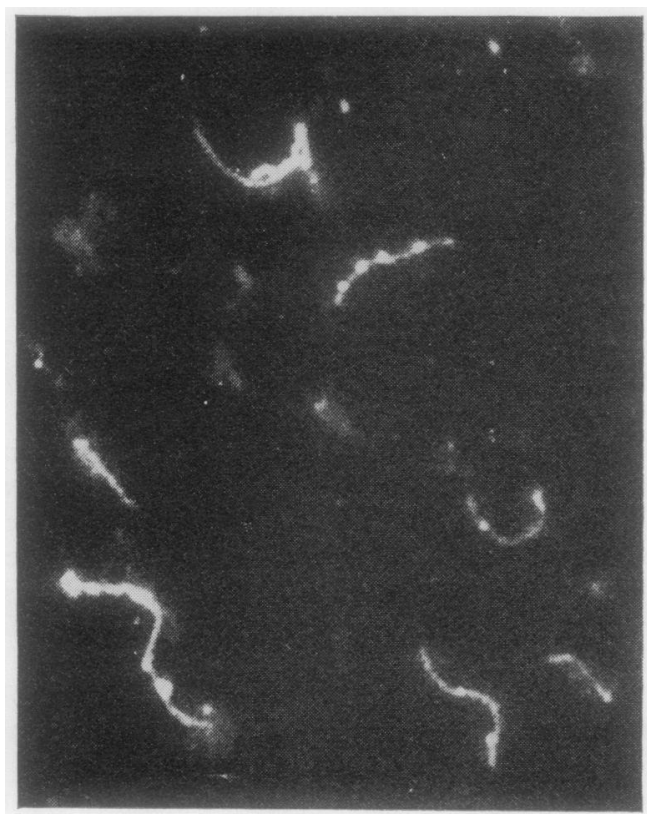

Fig. T. pallidum treated with sera from a patient with disseminated lupus erythematosus and followed by antihuman gamma fluorescein conjugates. Beaded (discontinuous) treponemal fluorescence seen in the same section as almost homogenous (continuous) staining pattern. $\times 1260$

geneous staining pattern. All had positive confirmatory tests for syphilis. When the fluorescent treponemal antibody absorption test was carried out, six sera from patients with syphilis, three from early and three from late cases, were unaffected by the $\stackrel{D^{\circ}}{=}$ pretreatment of treponemal antigen with the enzyme $\underline{\text { ㅇ }}$ deoxyribonuclease. Immunofluorescence on pre- $\overrightarrow{\vec{F}}$ treated treponemal substrates was tested in nine $\stackrel{9}{\stackrel{9}{9}}$ lepromatous leprosy sera which contained fluorescent treponemal antibodies. It was found that the staining pattern persisted.

The sera from the patients with collagen disorders, $\triangle$ which gave positive Reiter protein complement \& fixation and treponemal haemagglutination tests, $\vec{\circ}$ like the sera from patients with syphilis, failed to stain $T$. cruzi or $T$. gondii. Five out of six sera from $\vec{\omega}$ patients with collagen disorders who had negative confirmatory tests for syphilis, but positive fluore- ? scent treponemal antibody reactions, stained the $\stackrel{\sim}{\sigma}$ toxoplasma and trypanosomalantigens. Thisimmunofluorescent staining could again be abolished with Reiter treponemes. The immunofluorescent pattern $\varnothing_{\infty}$ reported by Beck and Walker (1964) on $T$. O cruzi in systemic lupus erythematosus was not encountered, nor was there any peripheral toxoplasma staining, as described by Fletcher (1965). The 50 control sera from the venereal disease clinic did not stain any microbial substrate.

The application of the protozoal 'false' positive immunofluorescence was used to decide the speci $\overrightarrow{0}$ ficity of the fluorescent treponemal antibod absorption test in the sera from lepromatous lepros The 14 leprosy sera, which reacted in the treponem fluorescent test, failed to stain $T$. cruzi or $T$. gondii. Eight of the remaining 81 lepromatous leprosy sera reacted against $T$. gondii and no sera stained $T$. cruzi. The results are summarized in table II.

It was concluded that these leprosy sera had

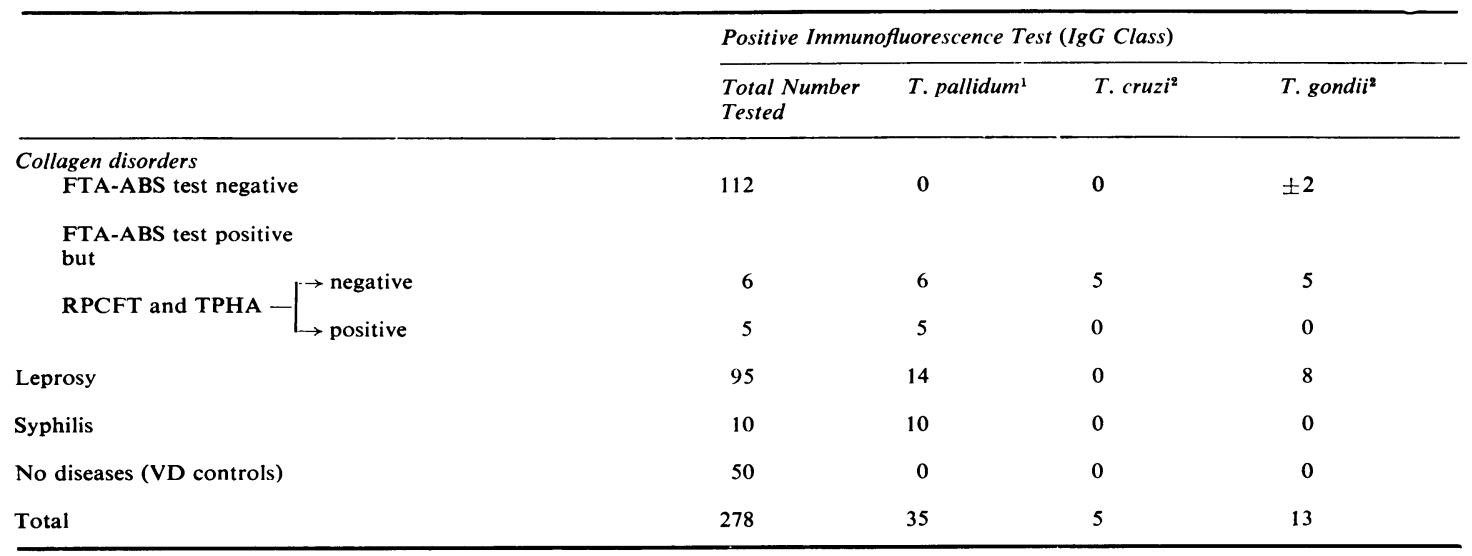

Table II Immunofluorescent tests using $\mathrm{T}$. pallidum, $\mathrm{T}$. cruzi, and $\mathrm{T}$. gondii substrates with sera from patients with collagen disorders, leprosy, and syphilis

${ }^{1}$ The diluent for $T$. pallidum was sorbent at $1 / 5$

${ }^{2}$ The diluent for $T$. cruzi and $T$. gondii was saline at $1 / 50$ 
specific antitreponemal antibodies, as the treponemal stain-persisted despite enzyme treatment of the substrates, while immunofluorescence on protozoa was not detected. This was confirmed by the presence of positive TPHA tests in the leprosy sera. No organ-specific antibodies were found in the leprosy sera.

Fifteen of the sera from patients with leprosy were re-examined for mitochondrial fluorescence and reactivity in the VDRL test.

Three sera gave positive fluorescent treponemal antibody absorption tests, of which two had positive VDRL agglutination tests and one had cardiolipin fluorescence. A positive VDRL test was found in one of the 11 remaining sera and mitochondrial fluorescence was found in low titre in seven of the 11 sera. This fluorescence could not be absorbed out by treatment with VDRL reagent, nor could the brightness be diminished. The immunoglobulin class of this ' $M$ ' fluorescence resided in IgG. The titres of the mitochondrial fluorescence could not be lowered by heating the sera at $56^{\circ} \mathrm{C}$ for two hours. No mitochondrial antibodies have previously been described in this disease.

\section{Discussion}

It has been suggested (Tringali and Cox, 1970) that low-titre fluorescent treponemal antibodies found in normal sera could be due to commensal spirochaetes. In relapsing fever in man (Alline and Marx, 1966) and experimental animals (Wright and Ginger, 1973) a positive fluorescent treponemal antibody is produced. The technique for the detection of the specific positive treponemal fluorescence in syphilis was to replace the saline diluent, diluted $1: 200$, with a substance which is better at absorbing out group antibody, namely, sorbent.

Neblett, Burnham, Merriam, and Fine (1966) suggested that the normal basal titres rise with polyclonal hypergammaglobulinaemia, causing a false positive fluorescent treponemal antibody (200) test. Kraus et al (1971) demonstrated that the false positive fluorescent treponemal antibody tests which occurred, despite the use of sorbent, in systemic lupus erythematosus were due to antibodies reacting against the DNA in treponemal 'nuclei'. Antibodies against DNA commonly occur in 'lupus' (Hughes, 1971) and can be removed by absorption with deoxyribonucleic acid (Kraus et al, 1971) or by pretreatment of the treponeme substrate with deoxyribonuclease. Not all the sera containing antibodies against antideoxyribonucleic acid gave the associated beaded pattern but many just stained homogenously like syphilitic sera. The differences in fixation of the treponemes may be responsible, as mixed patterns are seen side by side in the same section (figure). Thus improvements in technique by use of a better absorbent for group antibody is irrelevant since this would not affect antibodies against deoxyribonucleic acid. Reiter's treponeme shows a similar beaded pattern (Kraus et al, 1971) and so absorption with whole Reiter treponemes is effective but the method may not be foolproof as the efficiency of the absorption again depends on the titre of the antibodies against DNA. A definite immunofluorescent reaction against other parasites, at diagnostic titres, provided a simple alternative serum test for detecting the false positive reactions. The reliability of the test depends on how often antibodies to the parasite chosen are encountered. In this study, the rare trypanosome $T$. cruzi and the commoner $T$. gondii were used. Trypanosomiasis in England is a rarity; this is borne out by studies at the Seamen's Hospital, Greenwich, where not one positive reaction was found out of the 500 sera tested from their hospital population (personal observation). The possibility of positive treponemal, trypanosomal, and toxoplasmal tests indicating the presence of all three infections must be negligible in this country and makes the use of three tests a viable screening procedure. The finding of five out of 123 sera from patients with collagen disorders with positive tests for syphilis may indicate that syphilis is still a 'great mimic' in this group of patients. When the tests were carried out on sera from patients with lepromatous leprosy, the specificity of the fluorescent treponemal antibody absorption reactions was shown to be treponemal in origin as the trypanosomal and toxoplasmal tests were negative. The conclusion is strengthened by the persistence of antigenic sites for the FTA-ABS test, in DNAase pretreated treponemes, and the finding of a confirmatory test for syphilis in these leprosy sera. The disease process detected by the FTA-ABS tests was probably yaws which is endemic in Malaya (Turner, 1951). The inability to find any organspecific antibodies in leprosy (Wright, 1973) provides further support for the contention that autoimmune phenomena in leprosy and collagen disorders are distinct.

Several species of trypanosome gave nuclear staining with the immunofluorescent test in systemic lupus erythematosus (Beck and Walker, 1954). The staining pattern could also be eliminated by absorption by calf deoxyribonucleic acid, or pretreating the trypanosome with deoxyribonuclease. Similarly, antibodies to nuclear material in the Epstein-Barr DNA virus have also been reported in collagen disorders (Stevens, Stevens, Newell, Levin, and Waggonner, 1972), while in one case of Still's disease, Cat, Marinoni, Giraldi, and Costa 
(1971) found a serum which gave a positive reaction in the toxoplasmal immunofluorescent test at a titre of $1: 32000$ (significant titres $-1: 32-1: 64$ ). These findings suggest that antibodies against DNA might be mistaken for a specific antibody against a particular microbial antigen in collagen disorders and could well be related to the 'treponemal' antibodies described above. The finding in systemic lupus erythematosus of raised antibody titres against measles, which is a RNA virus, the titre being directly related to the degree of hypergammaglobulinaemia (Phillips and Christian, 1971) or to the presence of autoantibodies (Lucas, Brouwer, Feltkamp, ten Veen, and van Loghem, 1972), indicates that the raised antibody levels in these diseases are polyclonal and not necessarily against one type of antigenic determinant. However, with regard to syphilis, it is only the antibodies to deoxyribonucleic acid that are important.

I should like to thank Mr I. R. Nichols and the staff of the Interdepartmental Laboratory for their technical assistance, Professor M. H. Lessof and Dr A. G. Grimble (Guy's Hospital) for their advice and encouragement; also Dr M.F. R. Waters of the Sungoh Buloh Leprosarium and Dr R. J. W. Rees (National Institute of Medical Research, Mill Hill, NW7), for supplying the sera from patients with leprosy. I am grateful to Dr D. C. Fleck (PHLS, Tooting) for the R strain of toxoplasma and $\mathrm{Mr} \mathrm{B}$. Condom (Seaman's Hospital, Greenwich) for the lyophilized trypanosomes.

\section{References}

Allinne, M., and Marx, R. (1966). Le diagnostic des borrélioses par immunofluorescence. Ann. Inst. Pasteur, 111, Suppl., 28-35.

Beck, J. S., Walker, P. J. (1964). Antigenicity of trypanosome nuclei : Evidence that DNA is not coupled to histone in these protozoa. Nature (Lond.), 204, 194-195.
Cat, I., Marinoni, L. P., Giraldi, D. J., and Costa, O. (1971). False positive tests for toxoplasmosis in juvenile rheumatoid arthritis. Lancet, 2, 1156.

Fletcher, S. (1965). Indirect fluorescent antibody technique in the serology of Toxoplasma gondii. J. clin. Path., 18, 193-199.

Goldman, M. (1968). Fluorescent Antibody Methods. Academic Press, New York.

Hughes, G. R. V.(1971). Significance of anti-DNA antibodies in systemic lupus erythematosus. Lancet, 2, 861-863.

Johnston, N. A. (1972). Treponema pallidum haemagglutination test for syphilis. Brit. J. vener. Dis., 48, 474-478.

Kraus, S. J., Haserick, J. R., and Lantz, M. A. (1970). Fluorescent treponemal antibody absorption test reactions in lupus $\mathrm{O}$ erythematosus. New Engl. J. Med., 282, 1287-1290.

Kraus, S. J., Haserick, J. R., Logan, L. C., and Bullard, J. C. (1971). $\vec{O}$ A typical fluorescence in the fluorescent treponemal antibodyabsorption (FTA-ABS) test related to deoxyribonucleic acid $\vec{\omega}$ (DNA) antibodies. J. Immunol., 106, 1665-1669.

Lucas, C. J., Brouwer, R., Feltkamp, T. E. W., Ten Veen, J. H., and Van Loghem, J. J. (1972). Measles antibodies in sera from patients with autoimmune disease. Lancet, 1, 115-116.

National Communicable Disease Centre (1969). Manual of Tests for $\mathcal{O}$ Syphilis (revised) (Public Health Service Publication, No. 411). $\vec{N}$ U.S. Government Printıng Office, Atlanta, Georgia and Washington, D.C.

Neblett, T. R., Burnham, T. K., Merriam, L. R., and Fine, G. (1966). $\infty$ Treponemal antibodies in non-syphilitic, positive anti-nuclear $\mathrm{O}$ factor sera. J. invest. Derm., 46, 84-90.

Phillips, P. E., and Christian, C. L. (1972). The influence of serum immunoglobulin concentration on measles antibody level. Proc. Soc. exp. Biol. (N.Y.), 140, 1340-1343.

Scotti, A. T., Mackey, D. M., and Trautman, J. R. (1970). Syphilis and biologic false positive reactors among leprosy patients. Arch. Derm., 101, 328-330.

Stevens, D. A., Stevens, M. B., Newell, G. R., Levin, P. H., and Waggonner, D. E. (1972). Epstein-Barr virus (herpes-type virus) antibodies in connective tissue diseases. Arch. intern. 6 Med., 130, 23-28.

Tringali, G. R., and Cox, P. M. (1970). Reactivity in the FTA-A test of rabbits hyperimmunized with non-pathogenic trep nemes. Brit. J. vener. Dis., 46, 313-317.

Turner, L. H. (1959). Notes on the treponematoses. Bull. Inst. mead. Res. Malaya, 9.

Wilkinson, A. E. (1969). Serological tests for syphilis' (Revised). Ass. Clin. Path. Broadsheets 41.

World Health Organization (1969). Manual of Auto-immune Serology. WHO, Geneva.

Wright, D. J. M. (1973). Autoantibodies in leprosy. Lancet, 2, 40. $\overrightarrow{\bar{O}}$

Wright, D. J. M., Doniach, D., Lessof, M. H., Turk, J. L., Grimble, A. S., and Catterall, R. D. (1970). New antibody in early syphilis. Lancet, 1, 740-744.

Wright, D. J. M., and Ginger, C. D. (1973). Syphilitic immunofluorescence in experimental relapsing fever. Brit.J. vener. Dis. 49, 239-241. 